\title{
Foundations of Natural Language Grammar
}

\author{
Ruth Kempson • Glyn Morrill
}

\section{Erratum to: Res Lang Comput (2007) 5(3): 265-266 DOI 10.1007/s11168-007-9036-0}

We miss-spelled one of the author's names. The error occurs in the third paragraph. The first line and name should read:

In Separating Syntax and Combinatorics in Categorial Grammar, Muskens illustrates a categorial architecture called 'Lambda Grammars' comprising a tectogrammatical level of linear $\lambda$-terms relating pointwise a phenogrammatical dimension of form and a semantic dimension of meaning.

The online version of the original article can be found under doi:10.1007/s11168-007-9036-0.

\section{R. Kempson $(\varangle)$}

Department of Philosophy, King's College London, London WC2 R 2LS, UK e-mail: ruth.kempson@kcl.ac.uk

G. Morrill

Universitat Politec̀nica de Catalunya, Jordi Girona Salgado 1-3, 08028 Barcelona, Spain e-mail: morrill@1si.upc.es 